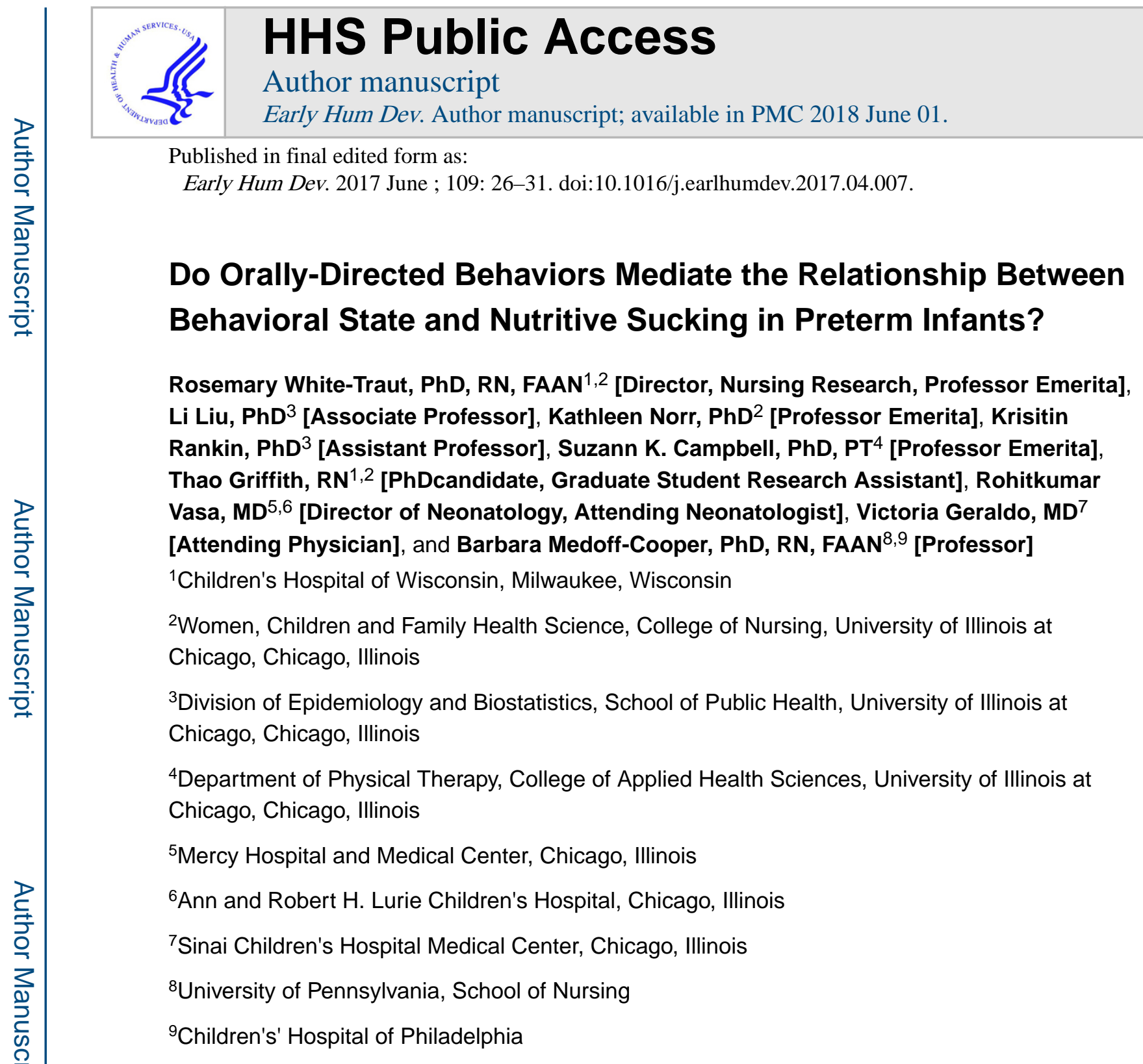

\title{
Introduction
}

Despite the advancement of assessment and interventions to facilitate oral feeding, many infants born preterm are challenged to achieve full oral feeding [1]. Although infant behavioral state is predictive of nutritive sucking patterns [2-4], less is known regarding the role of orally-directed behaviors (e.g. mouthing, tonguing, rooting, hand-to-mouth, suckingon-hand) in facilitating nutritive sucking patterns. Orally-directed behaviors are a sensitive

Corresponding Author: Rosemary White-Traut PhD, RN, FAAN, Director, Nursing Research, Nursing Research Department, Children's Hospital of Wisconsin, 9200 Wisconsin Avenue, Milwaukee, Wisconsin 53201-1997, 414-955-3613(office), 414-955-6337 (fax), rwhitetraut@chw.org.

Conflict of Interest Statement: The authors wish to confirm that there are no known conflicts of interest associated with this publication and there has been no significant financial support for this work that could have influenced its outcome.

Publisher's Disclaimer: This is a PDF file of an unedited manuscript that has been accepted for publication. As a service to our customers we are providing this early version of the manuscript. The manuscript will undergo copyediting, typesetting, and review of the resulting proof before it is published in its final citable form. Please note that during the production process errors may be discovered which could affect the content, and all legal disclaimers that apply to the journal pertain. 
indicator of the infant's behavioral organization $[5,6]$ and infants exhibit these behaviors to communicate their readiness to feed. Clinical observations suggest that alert infants exhibit an increased frequency of orally directed behaviors, yet it is unknown whether an alert state influences an increase in the frequency of orally directed behaviors or whether orally directed behaviors mediate the relationship between alert states and nutritive sucking organization. If these relationships exist, the findings would support the assessment of orally directed behaviors in clinical practice as well as the development and testing of interventions that enhance both alert states and an increased frequency of orally directed behaviors to facilitate oral feeding. Therefore, this study evaluated whether the frequency of orallydirected behaviors mediates the relationship between the proportion of time in alert states and a nutritive sucking metric the sucking maturity index (SMI).

\section{Behavioral States}

Behavioral state organization supports the infant's ability to coordinate the sensory, autonomic, and motor systems yielding optimal neurobehavioral organization [7-10]. In both preterm and full term infants, a predictable pattern of state development has been observed which is characterized by a decrease in active sleep and an increase in quiet sleep, alert states, and sleep state organization [11-17]. Differences in the pattern of behavioral states have been noted in infants born at 34, 37, and 40 weeks gestation [18]. Immature development of cortical organization, particularly in the frontal and prefrontal regions that control behavioral states may contribute to these observed differences [19]. Of the different categories of behavioral states, the alert behavioral state is considered optimal for oral feeding [20-26]. In preterm infants, the alert behavioral state is associated with improved feeding efficiency $[17,27]$ and is positively associated with improved nutritive sucking, including greater quantity, harder sucking pressure, a more complex pattern of bursts, and greater consistency of sucking waves [2-4]. The ability to achieve and maintain alert behavioral states prior to and during oral feeding is thought to be related to oral feeding success [20-26]. However, preterm infants are often challenged to achieve an alert behavioral state, and have greater difficulties remaining alert during oral feeding [13, 20, 21, 23]. Infants who are fed in other states, e.g., drowsy or sleep states, show poorer nutritive sucking, potentially leading to choking and aspiration [13, 20, 21, 23]. Behavioral state is an important indicator of oral feeding success and should be assessed carefully prior to and during feeding to support safe and efficient oral feeding [27].

\section{Orally-directed Behaviors}

Orally-directed behaviors are a sensitive indicator of the infant's behavioral organization and communicate to the caregiver the infant's readiness to feed $[5,6]$. They include mouthing, tonguing, rooting, hand-to-mouth, and sucking-on-hand [6, 17, 26, 28]. In full term infants, orally-directed behaviors emerge in the first hour following birth. Orally-directed behaviors are critical indicators of organized oromotor neurobehaviors, reflective of the infant's ability to self-comfort and regulate behavioral states [10]. After full term birth, mouthing and rooting occur within 3 to 21 minutes, sucking within 15 minutes, tonguing within 15-27 minutes, and hand-to-mouth activity within 12-34 minutes [29-32]. Orally-directed behaviors also support self-regulation, e.g., transition from crying to calm occurs when the infant is able to maintain sucking-on-hand activity [5]. Repeated attempts of swiping at the 
mouth are considered a less organized behavior compared to a sustained behavior such as a successful and sustained hand to the mouth [5]. Full term infants who demonstrate a high frequency of orally-directed behaviors are more successful with breastfeeding [29-31, 33, 34]. In cue-based feeding protocols, practitioners use a combination of alert behavioral states and the inability to settle after position/diaper change as assessment of the infant's readiness to feed [35-40]. Although orally-directed behaviors may be useful in evaluation of readiness for oral feeding, it is unknown what role they have in supporting nutritive sucking and clinical assessment of these behaviors prior to oral feeding is not routinely conducted, likely due to a lack of understanding regarding the role they play for preparation for feeding.

\section{Nutritive Sucking}

Nutritive sucking is an early motor skill and is critical to successful oral feeding [41-43]. Nutritive sucking is controlled by central pattern generators in the brain [41]. External and internal stimuli send signals to initiate the central pattern generators that influence the coordination of sucking, swallowing, and breathing [41]. Successful nutritive sucking results from the complex integration of muscular activities of the lips, cheeks, jaws, tongue, and palate while maintaining an alert behavioral state and coordinating sucking, swallowing, and breathing $[44,45]$. A mature nutritive sucking pattern is demonstrated by an increase in the number of sucks, sucks per burst, sucking pressure, and shorter inter-burst width (length of time between sucking bursts) [46-48]. The rhythmic alternation of suction (negative intraoral pressure to draw milk into the mouth) and expression (compression/stripping of the nipple to eject milk into the mouth) are all evidence of mature nutritive sucking [44, 49]. Health status (morbidity), birthweight, maturity (gestational age (GA) and postmenstrual age (PMA)), feeding experience, gender and pre-feeding behavioral state are known predictors of mature sucking patterns [2, 4, 45, 50-55]. Oral feeding performance is correlated with the organization of sucking patterns and regularity of sucking pressure $[44,56]$. Immature nutritive sucking consists of a low intensity sucking pressure which results in low milk intake which is associated with later developmental delays [42, 57]. Nutritive sucking is correlated with behavioral states [2-4]. Barlow hypothesized that behavioral state may affect peripheral and ascending input, activating the sensorimotor cortex and cerebellum that modulate central pattern generators to activate nutritive sucking [41]. Although nutritive sucking is clearly an important indicator of oral feeding success, little is understood regarding the potential for orally-directed behaviors to mediate the relationship between alert behavioral states and nutritive sucking. While, clinical observations suggest that alert infants exhibit an increased frequency of orally directed behaviors, it remains unknown whether an alert state influences an increase in the frequency of orally directed behaviors or whether orally directed behaviors mediate the relationship between alert states and nutritive sucking organization. If these relationships exist, interventions that support both alert states and an increased frequency of orally directed behaviors can be developed and studied.

\section{Purpose}

The purpose of this study was to evaluate whether the frequency of orally-directed behaviors mediates the relationship between the proportion of time in alert states and a nutritive sucking metric, the sucking maturity index (SMI). 


\section{Materials and Methods}

\section{Design}

The data for this secondary analysis were obtained from a larger randomized controlled trial (RCT) of a maternally administered developmental intervention for preterm infants [58]. For the larger study, behavioral state, orally-directed behaviors, and nutritive sucking metrics were collected weekly during the infant's hospitalization. For this report, we analyzed data from the second week (Day 7) of the RCT because infants had been receiving oral feeding for one week.

\section{Sample and Setting}

The RCT was conducted in 2 inner-city community-based Chicago medical centers. One had a Level II Special Care Nursery with extended capabilities, and one had a Level III Special Care Nursery. The Institutional Review Boards at the two clinical sites and the university approved the clinical trial. Prior to enrollment into the study, written informed consent was obtained from the mother. The target population was healthy premature infants born between 29 and 34 weeks GA, whose mothers had 2 or more social-environmental risks [58]. At both clinical sites, GA at birth was measured via the Ballard score (1991) [59]. Infants were eligible if they were clinically stable at the time of enrollment. Infants were not in oxygen, not septic, and receiving enteral feedings. Exclusion criteria included congenital anomalies, necrotizing enterocolitis, positive finding on head ultrasound (e.g. cystic periventricular leukomalacia or grade III or IV intraventricular hemorrhage), receiving assisted ventilation at the time of enrollment, chronic lung disease, and prenatal drug exposure. Infants from multiple births were recruited and particpated in the study, however, one was randomly selelcted for the analysis. There were no significant differences between the control and experimental groups for any of the infant characteristics (e.g. birthweight, sex, plurality, Apgar score, and PMA at observed feeding) at enrollment. Infants from the two groups were incldued in the mediation analyses.

\section{Measures}

\section{Infant Behavior}

Behavioral States: Seven categories of behavioral state (quiet sleep, active sleep, sleepwake transition, drowsy, alert, non-alert waking activity, and crying) developed by Thoman and modified by Holditch-Davis [8, 60-63] were used. These categories exhibit reliable individual differences and accurately profile the behavioral states of young preterm infants during the neonatal period [13, 64]. Infants were video-recorded for 30 minutes prior to a late morning feeding. The video recording was observed and behavioral state was judged for each 15 -second interval. The dominant behavioral state, i.e. the state occurring for $\geq 8$ seconds was selected and coded. From these codes, the proportion of time in the alert behavioral state was calculated. For this report, the proportion of time in the alert behavioral state for the minute immediately prior to the start of the oral feeding was computed and used for the analysis on Day 7, the second week of the infant's participation in the study. 
Orally-directed Behaviors: The frequencies of nine orally-directed behaviors (mouthing, tonguing, rooting, sucking on tongue, empty sucking, swipes-at-mouth, hand-to-mouth, sucking-on-hand, and yawning) were measured using the Cagan Videotape Coding System for Orally-directed Behaviors [6, 17, 26, 28]. Infants were video-recorded for 30 minutes prior to a late morning feeding. The video recordings for each time period were divided into 5 -second intervals prior to coding the frequency of orally-directed behaviors. For this report, the frequency of orally-directed behaviors exhibited in each 5-second interval was calculated for the minute immediately prior to the start of the feeding for Day 7 and was used in the analysis. Due to a highly skewed distribution for the mediator variable, frequency of orallydirected behaviors, we log-transformed it to minimize the impact of extreme values in the regression models.

Inter-rater Reliability: To establish inter-rater reliability prior to initiation of the study, the research assistants (blinded to the study's purpose) were trained to criterion (> 85\% agreement) to code the frequency of orally-directed behavioral cues and behavioral states. To assure continued inter-rater reliability, 25 of the video recordings were scored by the second research assistant.

Inter-rater reliability was determined using the intra-class correlation coefficient (ICC) [65]. Inter-rater reliability can be interpreted as very good to excellent when the ICC is 0.75 or higher. Twenty-five infants were randomly sampled and a second, independent rater coded orally-directed behavioral cues for those infants' second weekly observations using the same method described above. The total number of cues was summed for the minute immediately prior to the beginning of oral feeding. A second random sample of 25 infants was drawn and behavioral state was re-coded for that group by an independent rater for the second weekly observation.

For the proportion of time in alert behavioral states, inter-rater reliability resulted in an ICC of $0.993(0.983,0.997)$ for the minute immediately prior to the beginning of oral feeding. For orally-directed behavioral cues, inter-rater reliability resulted in an ICC $0.88(0.65,0.95)$ for the minute immediately prior to the beginning of oral feeding.

Nutritive Sucking - the Sucking Maturity Index (SMI): Nutritive sucking was evaluated via the SMI. The SMI was obtained via measurement of three metrics of nutritive sucking: number of sucks, mean number of sucks per burst, and the mean adjusted maximum pressure (MAMP). Nutritive sucking was digitally recorded using the Medoff-Cooper Nutritive Sucking Apparatus (M-CNSA) which was supported by the AcqKnowledge 3.9.0 software (BIOPAC, Goleta, CA). Nutritive sucking was measured on Day 7 for a 10 minute time period. The digital nutritive record was analyzed by Matlab 2007a (Natick, MA: The MathWorks) and a custom Matlab subroutine, Suck_Detect 1.1.12 software for the five minutes that were most representative of the ten minute feeding $[27,66]$. The SMI was derived by calculating and averaging the Z-scores for total number of sucks, number of sucks per burst and MAMP across the oral feeding session. 


\section{Procedure}

After written informed consent was obtained from the mother, infant characteristics were obtained from the medical record and included infant sex, plurality (singleton, twin, or triplet), GA at birth, small for GA, birthweight, type of delivery, 5-minute Apgar score, Problem Oriented Perinatal Risk Assessment Score (POPRAS) at birth [67], PMA at the baseline (Day 0) feeding observation, race/ethnicity, and hospital site.

Prior to the weekly 30-minute data collection session, the infant was moved from the NICU to an adjacent observation room. The infant was placed under a radiant warmer for 28 minutes for observation and the video recording was initiated. The infant was then transferred to the nurse while the video recording continued for 2 additional minutes. At the conclusion of the 30 minute video recording, the nipple was introduced and the oral feeding was initiated. The weekly data collection sessions were conducted prior to a late morning feeding. Infants remained on their cardiac monitors during the data collection session. Behavioral states and orally-directed behaviors were later coded via review of the video recordings. Nutritive sucking was measured via the M-CNSA.

Each video was processed through the Mangold Interact software (Mangold Interact, Germany) that offers the ability to customize coding schemes, time code, and enter the coded data directly into a database that captures all subjects. Orally-directed behaviors and behavioral states were judged for the one minute time segment by the Infant Behavior Research Assistant (RA) who was blinded to the purpose of the study.

\section{Statistical Analysis}

Descriptive statistics were computed for all infant characteristics (See Table 1), outcome (SMI), and the potential mediator variable, frequency of orally-directed behaviors. To examine the potential mediation mechanism, we followed the approach by Baron and Kenny (1996) [68] and ran three sets of linear regression models. Model 1 was conducted to predict the outcome of SMI using the proportion of alert states. This would establish the total effect of alert states on the outcome SMI without taking orally-directed behaviors into account. In Model 2, we attempted to establish the mediation path by the use of two regression relationships, predicting orally-directed behaviors (potential mediator) using alert states, and predicting the outcome SMI using the mediator, orally-directed behaviors. Lastly, in Model 3 , we evaluated the remaining effect of alert states on the outcome, SMI, after taking into account the indirect path through the mediator, orally-directed behaviors. In each regression model we adjusted for infant characteristics, birthweight, sex, plurality, Apgar score, and PMA at the observed feeding, which were included in the models as covariates. In the selection of infant characteristics to be adjusted in the regression models, backward selection was employed controlling for a probability of Type I error of 0.05 . The point-estimate of the indirect effect from alert states to the mediator, and from the mediator to the outcome variable is calculated by taking the difference between the two regression coefficients: effects of alert states on the outcome from models 1 and 3 [69]. Significance of the indirect effect was established using both the Sobel's Test (Standard Error in Table 3) and a more powerful Bootstrapping method, as the Sobel's Test is considered a low-power procedure for 
a moderate sample size such as ours [70]. The inference of indirect effect was obtained using the $\mathrm{R}$ package for mediation [71].

\section{Results}

Sixty-nine infants who remained in the RCT on Day 7 were eligible for this analysis. The sample consisted of $51.43 \%$ male infants and $85.71 \%$ singletons. $58.57 \%$ of mothers selfidentified as African-American and $41.43 \%$ as Latina. Infants had a mean GA at birth of 32.4 weeks, birthweight of $1758 \mathrm{~g}, 5$-minute Apgar score of 8.2, POPRAS score at birth of 68.4, and PMA of 34.8 weeks at the feeding session on Day 7. The mean for SMI was 0.10 $(S D=0.81)$, and the proportion of time spent in an alert behavioral state was $0.36(S D=$ 0.42 ) and the mean frequency of orally-directed behaviors for the minute immediately prior to feeding was $6.99(S D=7.78)$ (See Table 1).

In Model 1, there was a statistically significant total effect of alert states on the outcome SMI, without taking into account the mediator of orally-directed behavior $(\beta=.43, p=$ 0.039) (See Table 2). Model 2 revealed a partially significant indirect path, consisting of a significant relationship from alert states to orally-directed behaviors $(\beta=.85, p=0.007)$, and a non significant relationship from orally-directed behaviors to the outcome SMI $(\beta=.13, p$ $=0.141$ ). In Model 3, the direct effect of proportion of time in alert behavioral states on the outcome, which had been significant in Model 1, became non-significant $(\beta=0.33, p=$ 0.136). The indirect effect from alert states to orally-directed behaviors, to the SMI was estimated to be 0.11 , which is just short of statistical significance as suggested by the bootstrap method ( $p=0.073$ ) (See Tables 2 and 3). From our sample, the effect of the mediator on the outcome variable, SMI, is non significant $(\beta=.13, p=0.141)$, yet is suggestive that the frequency of orally-directed behaviors has the potential of mediating the relationship between alert behavioral states and SMI.

Selected covariates were included in the regression models and included birthweight, sex, plurality, Apgar score, and PMA at observed feeding (See Table 2). The significant covariate that predicted SMI was birthweight

\section{Discussion}

This is the first report evaluating the role of orally-directed behaviors as a potential mediator of alert behavioral states and nutritive sucking. Innovative measures of orally-directed behaviors and sucking patterns were used to evaluate infant feeding. Orally-directed behaviors are a sensitive indicator of the infant's behavioral organization, perhaps even more sensitive than behavioral state [5,6]. Although the mediation analysis did not statistically confirm that orally-directed behaviors mediate the relationship of alertness with the SMI, a trend was noted. These data provide preliminary evidence of the important role of orallydirected behaviors, and suggest that these behaviors be regularly included in the evaluation of the infant's preparation and readiness for oral feeding.

With maturation, a predictable pattern of state development has been previously reported. These changes in the pattern of behavioral states have been noted in older preterm infants born at 34,37 , and 40 weeks gestation [18] and show a decrease in active sleep with a 
corresponding increase in quiet sleep, alert states, and sleep state organization over time [11-17]. Infants in our sample were younger, a mean of 32 weeks PMA at enrollment yet 34.8 weeks at observation, and reached alertness for a proportion of .36 for the minute prior to feeding. This proportion of alertness is consistent with previous reports. Our results also support previous reports regarding the achievement of alert behavioral states being optimal for oral feeding [17, 20-27], especially in regards to improved nutritive sucking [2-4]. The significant relationship between behavioral state and the SMI confirms that the alert state is a significant indicator of optimal nutritive sucking and should be assessed carefully prior to and during oral feeding to support safe and efficient oral feeding [27].

There are very few publications studying orally-directed behaviors in preterm infants and thus comparisons of these data with other reports are challenging. However, in the larger RCT from which these data were extracted, the frequency of the orally-directed behaviors increased with maturation [28]. Additionally in the same RCT, the proportion of the alert behavioral state and the frequency of orally-directed behaviors were significantly increased when a multisensory intervention was administered immediately prior to feeding. One previous report from preterm infants with an average of 34 weeks PMA on their first day of oral feeding showed that the total frequency of orally-directed behaviors during the four minutes immediately prior to feeding was predictive of feeding efficiency (duration of feeding time and volume intake) [17], and the behavior with the highest frequency was tonguing [26]. In our sample of infants 34.8 weeks PMA, infants exhibited a mean frequency of 6.99 orally-directed behaviors over the minute immediately prior to oral feeding. These data suggest the importance of the frequency of orally-directed behaviors, and additional research on this less studied indicator is warranted.

As expected, several covariates, birthweight, sex, plurality, Apgar score, and PMA at observed feeding, predicted SMI. This finding is consistent with previous reports that suggested these indicators were related to improved oral feeding $[2,4,17,26,45,50-55$, 72-75]. A mature nutritive sucking pattern was previously identified as an increase in the number of sucks, number of sucks per burst, sucking pressure, and a shorter inter-burst width [46-48]. In this report, the SMI was calculated by averaging the $\mathrm{z}$ scores of three nutritive sucking indicators, number of sucks, mean number of sucks per burst, and the mean adjusted maximum pressure. In the larger RCT the SMI was shown to be significantly improved when a multisensory intervention was administered immediately prior to feeding [76]. This finding in conjunction with the increase in the proportion of alert sates and the increased frequency of the orally-directed behaviors led us to this secondary analysis. Our finding is similar to the previous work of Bingham, Medoff-Cooper, and Pickler who reported that nutritive sucking is correlated with behavioral states [2-4]. Although nutritive sucking is clearly an important indicator of oral feeding success, little is understood regarding how the SMI is influenced by the path from alert behavioral states through orallydirected behaviors to nutritive sucking.

In summary, during the mediation model building, the results did not confirm orally-directed behaviors as a mediator between the frequency of orally-directed behaviors and the sucking maturity index. However, given the small sample size and a positive point estimate of the relationship between the potential mediator and the outcome, these results suggest that 
frequency of orally-directed behaviors is a potential mediator in the relationship between behavioral states and the SMI. The point-estimate of indirect effects for the SMI was not statistically significant using the less powerful Sobel's Test but just short of significance ( $p=$ 0.073) using the bootstrap method.

\section{Limitations}

This study had several limitations. The sample was limited to infants with a limited range of GA at birth who were from only two racial/ethnic backgrounds. All infants received their hospital care in two community hospitals from one Midwestern metropolitan area, further limiting generalizability. The small sample size may have limited the ability to detect statistical differences within the mediation model. The behavioral data were measured prior to feeding. Future studies should include a larger sample size and assessment of infant behavior both before and during feeding. Additionally, future research should include infants of different postmenstrual ages and data from more than one day of oral feeding to allow for a more in-depth understanding of infant maturation, behavior and nutritive sucking.

\section{Conclusion}

Although the alert behavioral state is a significant predictor of SMI, this mediation analysis did not support the hypothesis that such an effect is mediated by the frequency of orallydirected behaviors. However, this analysis provided valuable beginning evidence suggesting the direction of this mediation effect. Future research with a larger sample size is warranted to determine the existence of this potential mediation effect among behavioral states, orallydirected behaviors, and nutritive sucking.

\section{References}

1. Jadcherla SR, Wang M, Vijayapal AS, Leuthner SR. Impact of prematurity and co-morbidities on feeding milestones in neonates: a retrospective study. J Perinatol. 2010 Mar; 30(3):201-8. [PubMed: 19812589]

2. Medoff-Cooper B, McGrath JM, Bilker W. Nutritive sucking and neurobehavioral development in preterm infants from 34 weeks PCA to term. Am J Matern Child Nurs. 2000 Mar-Apr;25(2):64-70.

3. Bingham PM, Ashikaga T, Abbasi S. Relationship of behavioral state and tube-feeding to nonnutritive sucking in premature infants. J Neonatal Nurs. 2011; 17:150-7.

4. Pickler RH, Best AM, Reyna BA, Gutcher G, Wetzel PA. Predictors of nutritive sucking in preterm infants. J Perinatol. 2006 Nov; 26(11):693-9. [PubMed: 16988722]

5. Bell AF, White-Traut R, Rankin K. Fetal exposure to synthetic oxytocin and the relationship with prefeeding cues within one hour postbirth. Early Hum Dev. 2013 Mar; 89(3):137-43. [PubMed: 23084698]

6. Cagan J. Feeding readiness behavior in preterm infants. Neonatal Netw. 1995; 14(2):82.

7. Korner AF. State as variable, as obstacle, and as mediator of stimulation in infants research. Merrill Palmer Quarterly. 1972; 18:77-94.

8. Thoman EB. Sleeping and waking states in infants: A functional perspective. Neurosci Biobehav Rev. 1990; 14:93-107. [PubMed: 2183100]

9. Wolff, PH. Observations of early development of smiling. Foss, BM., editor. New York: John Wiley; 1966. p. 117-30.

10. Bell AF, Lucas R, White-Traut RC. Concept clarification of neonatal neurobehavioural organization. J Adv Nurs. 2008 Mar; 61(5):570-81. [PubMed: 18261065] 
11. Foreman SW, Thomas KA, Blackburn ST. Individual and gender differences matter in preterm infant state development. J Obstet Gynecol Neonatal Nurs. 2008; 37(6):657-65.

12. Holditch-Davis D, Scher M, Schwartz T, Hudson-Barr D. Sleeping and waking state development in preterm infants. Early Hum Dev. 2004 Oct; 80(1):43-64. Epub 2004/09/15. eng. [PubMed: 15363838]

13. Holditch-Davis D, Edwards LJ. Modeling development of sleep-wake behaviors. II. Results of two cohorts of preterms. Physiol Behav. 1998 Feb 1; 63(3):319-28. Epub 1998/02/20. eng. [PubMed: 9469722]

14. Whitney MP, Thoman EB. Sleep in premature and fullterm infants from 24-hour home recordings. Infant Bev Dev. 2004; 17:223-34.

15. Holditch-Davis D, Bartlett TR, Blickman AL, Miles MS. Posttraumatic stress symptoms in mothers of premature infants. J Obstet Gynecol Neonatal Nurs. 2003 Mar-Apr;32(2):161-71.

16. Holditch-Davis D. The development of sleeping and walking states in high-risk preterm infants. Infant Bev Dev. 1990; 13:513-31.

17. White-Traut R, Berbaum ML, Lessen B, McFarlin B, Cardenas L. Feeding readiness in preterm infants: the relationship between preterm behavioral states and feeding readiness behaviors and efficiency during transition from gavage to oral feeding. Am J Matern Child Nurs. 2005 Jan-Feb; 30(1):52-9.

18. Mouradian L, Als H, Coster W. Neurobehavioral functioning of healthy preterm infants of varying gestational ages. J Dev Behav Pediatr. 2000; 21(6):408-16. [PubMed: 11132791]

19. Duffy FH, Als H, McAnulty GB. Behavioral and electrophysiological evidence for gestational age effects in healthy preterm and fullterm infants studied two weeks after expected due date. Child Dev. 1990 Aug; 61(4):271-86. [PubMed: 2209195]

20. Panniers TL. Refining clinical terminology for expert system development: an application in the neonatal intensive care unit. Pediatr Nurs. 2002 Sep-Oct;28(5):519-3. Epub 2002/11/12. eng. [PubMed: 12424990]

21. McGrath JM, Medoff-Cooper B. Alertness and feeding competence in extremely early born preterm infants. Newborn Infant Nurs Rev. 2002; 2(3):174-86.

22. McCain GC. Promotion of preterm infant nipple feeding with nonnutritive sucking. J Pediatr Nurs. 1995 Feb; 10(1):3-8. [PubMed: 7891260]

23. McCain GC. Behavioral state activity during nipple feedings for preterm infants. Neonatal Netw. 1997; 16(5):43-7.

24. Gill NE, Behnke M, Conlon M, Anderson GC. Nonnutritive sucking modulates behavioral state for preterm infants before feeding. Scand J Caring Sci. 1992; 6(1):3-7. [PubMed: 1579769]

25. Pickler RH, Best AM, Reyna BA, Wetzel PA, Gutcher GR. Prediction of feeding performance in preterm infants. Newborn Infant Nurs Rev. 2005 Sep; 5(3):116-23. Epub 2006/02/10. Eng. [PubMed: 16467910]

26. White-Traut R, Nelson MN, Silvestri JM, Vasan U, Patel M, Cardenas L. Feeding readiness behaviors and feeding efficiency in response to ATVV intervention. Newborn Infant Nurs Rev. 2002; 2(3):166-73.

27. Griffith T, Rankin K, White-Traut R. The relationship between behavioral states and oral feeding efficiency in preterm infants. Advance in Neonatal Care. In press.

28. White-Traut R, Rankin RM, Pham T, Zhuoying L, Liu L. Preterm infant's orally directed behaviors and behavioral state responses to the integrated H-HOPE intervention. Infant Behav Dev. 2014; 37(4):583-96. [PubMed: 25189523]

29. Matthiesen AS, Ransjo-Arvidson AB, Nissen E, Uvnas-Moberg K. Postpartum maternal oxytocin release by newborns: effects of infant hand massage and sucking. Birth. 2001 Mar; 28(1):13-9. [PubMed: 11264623]

30. Ransjo-Arvidson AB, Matthiesen AS, Lilja G, Nissen E, Widstrom AM, Uvnas-Moberg K. Maternal analgesia during labor disturbs newborn behavior: effects on breastfeeding, temperature, and crying. Birth. 2001 Mar; 28(1):5-12. Epub 2001/03/27. eng. [PubMed: 11264622]

31. Widstrom AM, Ransjo-Arvidson AB, Christensson K, Matthiesen AS, Winberg J, Uvnas-Moberg K. Gastric suction in healthy newborn infants. Effects on circulation and developing feeding behaviour. Acta Paediatr Scand. 1987 Jul; 76(4):566-72. [PubMed: 3630673] 
32. Widstrom AM, Lilja G, Aaltomaa-Michalias P, Dahllof A, Lintula M, Nissen E. Newborn behaviour to locate the breast when skin-to-skin: a possible method for enabling early selfregulation. Acta Pædiatr. 2011 Jan; 100(1):79-85. Epub 2010/08/18. eng.

33. Erlandsson K, Dsilna A, Fagerberg I, Christensson K. Skin-to-skin care with the father after cesarean birth and its effect on newborn crying and prefeeding behavior. Birth. 2007 Jun; 34(2): 105-14. [PubMed: 17542814]

34. Hentschel J, Ruff R, Juette F, von Gontard A, Gortner L. Neonatal facial movements in the first minutes of life--eye opening and tongue thrust: an observational study. Am J Perinatol. 2007 Nov; 24(10):611-8. Epub 2007/11/01. eng. [PubMed: 17972233]

35. Children's Hospital of Wisconsin tr. Cue-based Feeding. 2008 [Evidence-based practice guideline] In press.

36. Thoyre SM, Park J, Pados B, Hubbard C. Developing a co-regulated, cue-based feeding practice: The critical role of assessment and reflection. J Neonatal Nurs. 2013; 19(4):139-48. [PubMed: 25814831]

37. Kirk AT, Alder SC, King JD. Cue-based oral feeding clinical pathway results in earlier attainment of full oral feeding in premature infants. J Perinatol. 2007 Sep; 27(9):572-8. [PubMed: 17625573]

38. Puckett B, Grover VK, Holt T, Sankaran K. Cue-based feeding for preterm infants: a prospective trial. Am J Perinatol. 2008 Nov; 25(10):623-8. [PubMed: 18841533]

39. Jadcherla SR, Peng J, Moore R, Saavedra J, Shepherd E, Fernandez S, et al. Impact of personalized feeding program in 100 NICU infants: pathophysiology-based approach for better outcomes. J Pediatr Gastroenterol Nutr. 2012 Jan; 54(1):62-70. [PubMed: 21694638]

40. McCain GC, Gartside PS, Greenberg JM, Lott JW. A feeding protocol for healthy preterm infants that shortens time to oral feeding. J Pediatr. 2001 Sep; 139(3):374-9. [PubMed: 11562616]

41. Barlow SM, Poore M, Zimmerman EA, Finan D. Feeding skills in the preterm infants2010. May 14.2013

42. Medoff-Cooper B, Shults J, Kaplan J. Sucking behavior of preterm neonates as a predictor of developmental outcomes. J Dev Behav Pediatr. 2009 Feb; 30(1):16-22. [PubMed: 19194323]

43. Lucas R, White-Traut R, Rankin K, Wang E, Medoff-Cooper B. The emergence of a nutritive suck in preterm infants. 2011 [Manuscript submitted for publication]. In press.

44. Lau C, Geddes D, Mizuno K, Schaal B. The development of oral feeding skills in infants. Int J Pediatr. 2012; 2012:572341. [PubMed: 23193413]

45. Mizuno K, Ueda A. The maturation and coordination of sucking, swallowing, and respiration in preterm infants. J Pediatr. 2003 Jan; 142(1):36-40. [PubMed: 12520252]

46. Medoff-Cooper B, Bilker W, Kaplan JM. Sucking patterns and behavioral state in 1- and 2-day-old full-term infants. J Obstet Gynecol Neonatal Nurs. 2010 Sep-Oct;39(5):519-24.

47. Medoff-Cooper B, McGrath JM, Shults J. Feeding patterns of full-term and preterm infants at forty weeks postconceptional age. J Dev Behav Pediatr. 2002 Aug; 23(4):231-6. [PubMed: 12177569]

48. Medoff-Cooper B, Ratcliffe SJ. Development of preterm infants: feeding behaviors and brazelton neonatal behavioral assessment scale at 40 and 44 weeks' postconceptional age. Adv Nurs Sci. 2005 Oct-Dec;28(4):356-63.

49. Lau C, Alagugurusamy R, Schanler RJ, Smith EO, Shulman RJ. Characterization of the developmental stages of sucking in preterm infants during bottle feeding. Acta Paediatr. $2000 \mathrm{Jul}$; 89(7):846-52. [PubMed: 10943969]

50. Matsubara M, Tamura Y, Ruchala P. Analysis of nutritive sucking function in very low and extremely low birthweight infants in Japan: a pilot study. Jpn J Nurs Sci. 2005; 2(1):3-7.

51. Hafstrom M, Kjellmer I. Non-nutritive sucking in the healthy pre-term infant. Early Hum Dev. 2000 Nov; 60(1):13-24. [PubMed: 11054580]

52. Cunha M, Barreiros J, Goncalves I, Figueiredo H. Nutritive sucking pattern--from very low birth weight preterm to term newborn. Early Hum Dev. 2009 Feb; 85(2):125-30. [PubMed: 18768269]

53. Medoff-Cooper B. Response to letter regarding : "Changes in nutritive sucking patterns with increasing gestational age”. Nurs Res. 1992; 41(2):126-7. [PubMed: 1549518]

54. Medoff-Cooper B. Changes in nutritive sucking patterns with increasing gestational age. Nurs Res. 1991 Jul-Aug;40(4):245-7. [PubMed: 1857653] 
55. Medoff-Cooper B, Verklan T, Carlson S. The development of sucking patterns and physiologic correlates in very-low-birth-weight infants. Nurs Res. 1993 Mar-Apr;42(2):100-5. [PubMed: 8455984]

56. Bingham PM, Ashikaga T, Abbasi S. Prospective study of non-nutritive sucking and feeding skills in premature infants. Arch Dis Child Fetal Neonatal Ed. 2010 May; 95(3):F194-200. [PubMed: 19948525]

57. Medoff-Cooper B, Gennaro S. The correlation of sucking behaviors and Bayley Scales of Infant Development at six months of age in VLBW infants. Nurs Res. 1996 Sep-Oct;45(5):291-6. [PubMed: 8831656]

58. White-Traut R, Norr K. An ecological model for premature infant feeding. J Obstet Gynecol Neonatal Nurs. 2009 Jul-Aug;38(4):478-89. quiz 89-90, Epub 2009/07/21. eng.

59. Ballard JL, Khoury JC, Wedig K, Wang L, Eilers-Walsman BL, Lipp R. New Ballard Score, expanded to include extremely premature infants. J Pediatr. 1991 Sep; 119(3):417-23. Epub 1991/09/01. eng. [PubMed: 1880657]

60. Holditch-Davis D, Thoman EB. Behavioral states of premature infants: implications for neural and behavioral development. Dev Psychobiol. 1987; 20(1):25-38. [PubMed: 3556782]

61. Thoman EB, Korner AF, Kraemer HC. Individual consistency in behavioral states in neonates. Dev Psychobiol. 1976 May; 9(3):271-83. Epub 1976/05/01. eng. [PubMed: 182605]

62. Thoman EB, Davis DH, Raye JR, Philipps AF, Rowe JC, Denenberg VH. Theophylline affects sleep-wake state development in premature infants. Neuropediatrics. 1985; 16:13-8. [PubMed: 3974797]

63. Thoman EB. The sleeping and waking states of infants: Correlations across time and person. Physiol Behav. 1987; 41:531-7. [PubMed: 3441523]

64. Holditch-Davis D, Edwards LJ, Helms RW. Modeling development of sleep-wake behaviors: I. Using the mixed general linear model. Physiol Behav. 1998; 63(3):311-8. [PubMed: 9469721]

65. Fleiss, JL. Statistical methods for rates and proportions. 2nd. New York: John Wiley; 1981.

66. White-Traut R, Shapiro N, Healy-Baker E, Menchavez L, Rankin K. Lack of feeding progression in a preterm infant: A case study. Adv Neonatal Care. 2013 Oct; 13(3):175-80. [PubMed: 23722488]

67. Davidson, EC., Hobel, CJ. POPRAS: A guide to using the prenatal, intrapartum, postpartum record. Torrence, CA: South Bay Regional Perinatal Project Professional Staff Association; 1978.

68. Baron RM, Kenny DA. The moderator-mediator variable distinction in social psychological research: conceptual, strategic, and statistical considerations. J Pers Soc Psychol. 1986 Dec; 51(6): 1173-82. Epub 1986/12/01. eng. [PubMed: 3806354]

69. Judd MC, Kenny DA. Process analysis: Estimating mediation in treatment evaluations. Evaluation Review. 1981; 5(5):602-19.

70. MacKinnon DP, Fairchild AJ, Fritz MS. Mediation analysis. Annu Rev Psychol. 2007; 58:593614. Epub 2006/09/14. eng. [PubMed: 16968208]

71. Imai K, Keele L, Tingley D. A general approach to causal mediation analysis. Psychol Methods. 2010 Dec; 15(4):309-34. Epub 2010/10/20. eng. [PubMed: 20954780]

72. Gewolb IH, Vice FL. Maturational changes in the rhythms, patterning, and coordination of respiration and swallow during feeding in preterm and term infants. Dev Med Child Neurol. 2006 Jul; 48(7):589-94. [PubMed: 16780629]

73. Gewolb IH, Vice FL, Schwietzer-Kenney EL, Taciak VL, Bosma JF. Developmental patterns of rhythmic suck and swallow in preterm infants. Dev Med Child Neurol. 2001 Jan; 43(1):22-7. [PubMed: 11201418]

74. Thoyre SM. Developmental transition from gavage to oral feeding in the preterm infant. Annu Rev Nurs Res. 2003; 21:61-92. Epub 2003/07/16. eng. [PubMed: 12858693]

75. Thoyre SM, Shaker CS, Pridham KF. The early feeding skills assessment for preterm infants. Neonatal Netw. 2005 May-Jun;24(3):7-16. Epub 2005/06/18. eng.

76. Medoff-Cooper B, Rankin K, Li Z, Liu L, White-Traut R. Multisensory intervention for preterm infants improves sucking organization. Adv Neonatal Care. 2015 Apr; 15(2):142-9. Epub 2015/03/31. eng. [PubMed: 25822519] 
Table 1

Descriptive Statistics for Infant Characteristics, Outcome, Independent, and Mediator Variables $(n=69)$

\begin{tabular}{|c|c|c|c|}
\hline Infant Characteristics & Percent & Mean $(S D)$ & Range \\
\hline \multicolumn{4}{|l|}{ Sex } \\
\hline Female & 51.43 & & \\
\hline Male & 48.57 & & \\
\hline \multicolumn{4}{|l|}{ Plurality } \\
\hline Singleton & 85.71 & & \\
\hline Twin/Triplet & 14.29 & & \\
\hline \multicolumn{4}{|l|}{ Small for gestational age } \\
\hline Yes & 28.57 & & \\
\hline No & 71.43 & & \\
\hline \multicolumn{4}{|l|}{ Type of delivery } \\
\hline NSVD & 58.57 & & \\
\hline C-SEC & 41.43 & & \\
\hline \multicolumn{4}{|l|}{ Site } \\
\hline A & 62.86 & & \\
\hline B & 37.14 & & \\
\hline \multicolumn{4}{|l|}{ Maternal race/ethnicity } \\
\hline Latina & 41.43 & & \\
\hline African-American & 58.57 & & \\
\hline Gestational age at birth, weeks & & $32.4(1.4)$ & \\
\hline Birthweight, grams & & $1758(331.0)$ & \\
\hline Apgar score $5 \mathrm{~min}$ & & $8.2(1.2)$ & \\
\hline Infant morbidity score at delivery (POPRAS score) & & $68.4(18.9)$ & \\
\hline Post-menstrual age at feeding observation (Day 7) & 34.8 & $34.8(1.0)$ & \\
\hline \multicolumn{4}{|l|}{ Outcomes Variable } \\
\hline Sucking Maturity Index (SMI) & & $0.10(0.81)$ & $-1.40-2.04$ \\
\hline \multicolumn{4}{|l|}{ Independent Variable } \\
\hline$\%$ of Time Spent in an Alert State & & $0.36(0.42)$ & $0.00-1.00$ \\
\hline \multicolumn{4}{|l|}{ Mediator Variables } \\
\hline Frequency of Orally-directed Behaviors & & $6.99(7.78)$ & $0.00-32.00$ \\
\hline
\end{tabular}

Note. $\mathrm{SD}=$ Standard deviation $; \mathrm{NSVD}=$ Non-spontaneous vaginal delivery $;$ C-SEC $=$ Cesarean section; POPRAS $=$ Problem-Oriented Perinatal Risk Assessment System; SMI = Sucking maturity index 


\section{Table 2}

Mediation Analysis for SMI $(n=69)$

\begin{tabular}{lllll}
\hline Model \# & Outcomes & Predictor of Interest & $\boldsymbol{\beta}(\boldsymbol{S E})$ & $\boldsymbol{p}$-value \\
\hline 1 & SMI & \% Alert States & $0.43(0.21)$ & 0.039 \\
& & Birthweight & $0.0009(0.0003)$ & 0.001 \\
& Sex (ref = female) & $-0.227(-1.31)$ & 0.196 \\
& Plurality (ref = singleton) & $0.468(0.255)$ & 0.083 \\
& Apgar Score & $0.1169(0.08)$ & 0.138 \\
& & PMA at feeding & $0.105(0.09)$ & 0.274 \\
& & \% Alert States & $0.85(0.31)$ & 0.007 \\
& \multirow{2}{*}{ Orally-directed Behaviors SMI } & Orally-directed Behaviors & $0.13(0.09)$ & 0.141 \\
& & Birthweight & $0.001(0.0004)$ & 0.11 \\
& & Sex (ref = female) & $-0.29(0.26)$ & 0.27 \\
& & Plurality (ref = singleton) $)$ & $0.43(0.39)$ & 0.28 \\
& Apgar Score & $0.18(0.11)$ & 0.12 \\
& PMA at feeding & $0.08(0.14)$ & 0.57 \\
& & \% Alert States & $0.33(0.09)$ & 0.136 \\
& SMI & Indirect Effect & $0.11(0.08)$ & 0.073 \\
& Birthweight & $0.001(0.0003)$ & 0.004 \\
& Sex (ref = female) & $-0.19(0.17)$ & 0.276 \\
& Plurality (ref = singleton) & $0.41(0.27)$ & 0.12 \\
& Apgar Score & $0.09(0.08)$ & 0.24 \\
& PMA at feeding & $0.09(0.09)$ & 0.32 \\
\hline
\end{tabular}

Note. Covariates adjusted in the models include birth eight (grams), sex, plurality, Apgar Score, and PMA at observed feeding. SE = Standard error; SMI = Sucking maturity index; PMA $=$ Post-menstrual age 

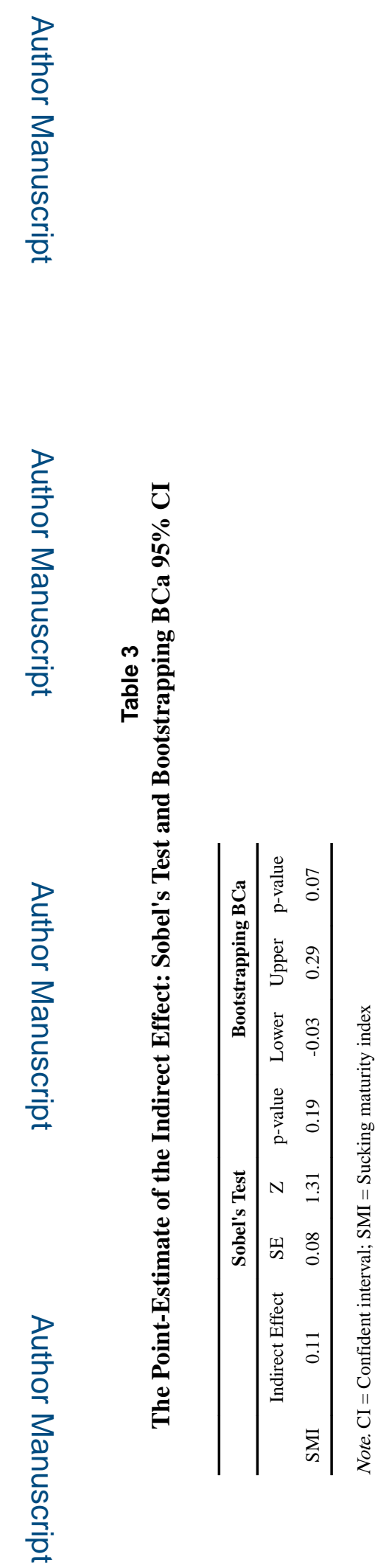

Early Hum Dev. Author manuscript; available in PMC 2018 June 01. 